\title{
Adapting a geographical information system-based water resource management to the needs of the Romanian water authorities
}

\author{
Marc Soutter • Maria Alexandrescu • Colin Schenk • \\ Radu Drobot
}

Received: 25 April 2008 /Accepted: 8 October 2008 /Published online: 8 November 2008

(C) Springer-Verlag 2008

\begin{abstract}
Background, aim, and scope The need for global and integrated approaches to water resources management, both from the quantitative and the qualitative point of view, has long been recognized. Water quality management is a major issue for sustainable development and a mandatory task with respect to the implementation of the European Water Framework Directive as well as the Swiss legislation. However, data modelling to develop relational databases and subsequent geographic information system (GIS)-based water management instruments are a rather recent and not that widespread trend. The publication of overall guidelines for data modelling along with the EU Water Framework Directive is an important milestone in this area. Improving overall water quality requires better and more easily accessible data, but also the possibility to link data to
\end{abstract}

Responsible editor: Water Giger

M. Soutter $(\square)$

Swiss Federal Institute of Technology,

Environmental Sciences and Technology Institute,

Ecohydrology Laboratory,

EPFL-Ecublens,

CH-1015 Lausanne, Switzerland

e-mail: marc.soutter@epfl.ch

M. Alexandrescu $\cdot$ R. Drobot

Universitatea Tehnica de Constructii Bucuresti,

Facultatea de Hidrotehnica,

bl. Lacul Tei 122-124,

Bucuresti 2, 38RO72302, Romania

C. Schenk

Swiss Federal Institute of Technology,

Environmental Sciences and Technology Institute,

Hydrology and Land Management Laboratory,

EPFL-Ecublens,

CH-1015 Lausanne, Switzerland simulation models. Models are to be used to derive indicators that will in turn support decision-making processes. For this whole chain to become effective at a river basin scale, all its components have to become part of the current daily practice of the local water administration. Any system, tool, or instrument that is not designed to meet, first of all, the fundamental needs of its primary end-users has almost no chance to be successful in the longer term.

Materials and methods Although based on a pre-existing water resources management system developed in Switzerland, the methodological approach applied to develop a GIS-based water quality management system adapted to the Romanian context followed a set of well-defined steps: the first and very important step is the assessment of needs (on the basis of a careful analysis of the various activities and missions of the water administration and other relevant stakeholders in water management related issues). On that basis, a conceptual data model (CDM) can be developed, to be later on turned into a physical database. Finally, the specifically requested additional functionalities (i.e. functionalities not provided by classical commercial GIS software), also identified during the assessment of needs, are developed. This methodology was applied, on an experimental basin, in the Ialomita River basin.

Results The results obtained from this action-research project consist of a set of tangible elements, among which (1) a conceptual data model adapted to the Romanian specificities regarding water resources management (needs, data availability, etc.), (2) a related spatial relational database (objects and attributes in tables, links, etc.), that can be used to store the data collected, among others, by the water administration, and later on exploited with geographical information systems, (3) a toolbar (in the ESRI environment) offering the requested data processing and visualizing functionalities. Lessons learned from this whole 
process can be considered as additional, although less tangible, results.

Discussion The applied methodology is fairly classical and did not come up with revolutionary results. Actually, the interesting aspects of this work are, on the one hand, and obviously, the fact that it produced tools matching the needs of the local (if not national) water administration (i.e. with a good chance of being effectively used in the day-to-day practice), and, on the other hand, the adaptations and adjustments that were needed both at the staff level and in technical terms.

Conclusions This research showed that a GIS-based water management system needs to be backed by some basic data management tools that form the necessary support upon which a GIS can be deployed. The main lesson gained is that technology transfer has to pay much attention to the differences in existing situations and backgrounds in general, and therefore must be able to show much flexibility. The fact that the original objectives could be adapted to meet the real needs of the local end-users is considered as a major aspect in achieving a successful adaptation and development of water resources management tools. Time needed to setup things in real life was probably the most underestimated aspect in this technology transfer process.

Recommendations and perspectives The whole material produced (conceptual data model, database and GIS tools) was disseminated among all river basin authorities in Romania on the behalf of the national water administration (ANAR). The fact that further developments, for example, to address water quantity issues more precisely, as envisaged by ANAR, can be seen as an indication that this project succeeded in providing an appropriate input to improve water quality in Romania on the long term.

Keywords Conceptual data model - ESTROM .

Geographical information system (GIS) ·

Ialomita River basin · Romania · Water authorities .

Water quality . Water resource management

\section{Background, aim, and scope}

The need for global and integrated approaches to water resources management, both from the quantitative and the qualitative point of view, has long been recognized. Integration appears as a mandatory step towards a more sustainable management of natural resources such as water and is therefore an ever more prominent aspect in the political agenda as well as in the regulations of many countries, as for instance in the EU Water Framework Directive, in the Swiss legislation, or in the New Water Policy in Quebec (MDDEP 2002).

Integration means basically to have the various interests and concerns linked to water management working togeth- er, which means a common spatial reference (ideally the river basin scale) and a participatory multi-stakeholder approach, at least to some extent (Abbot et al. 1998). Information sharing is probably the lowest possible level of collaborative interaction among a group of stakeholders (Borja and Castells 1997). It is also one of its most crucial aspects, since shared (and better) information is the basis for more rational discussions and better decisions. However, in the field of water management, using data modelling as a basis to develop relational databases and subsequent geographic information system (GIS)-based instruments are a rather recent and not that widespread trend (Lyon 2002). The publication of guidelines for data modelling along with the EU Water Framework Directive is an important milestone in this area (see for example EU 2003).

An overall improvement of water quality as a long-term effect of accessing better information more easily, namely spatial information, can well be imagined, while other more elaborated tools are also supposed to provide significant changes in the water management activities. These tools include the coupling with simulation models that can be used to derive indicators, themselves acting as a support in the decision-making process. However, for this whole chain to become effective at a river basin scale, all its components have to become part of the current daily practice of the local water administration. Any system, tool, or instrument that is not designed to meet the fundamental needs of its primary end-users first of all has almost no chance to be successful in the longer term.

The primary objective of this action-research project was to transfer and adapt to the Romanian context an operational GIS-based integrated water management tool, that has been developed and is currently in use in the canton de Vaud (Mattei and Soutter 2008). In Romania, the main end-users of the transferred and adapted GIS-based water management platform are the various river basin authorities as well as the central water administration in their daily practice. The development of the GESREAU ${ }^{1}$ water resources management GIS platform started back in the mid-80s, as a collaboration between the Swiss Federal Institute of Technology (EPFL) and the water authority of canton de Vaud (SESA). This, at the time innovating approach to address the ever growing number and diversity of the assignments given to the water administrations, needed several years of thoughtful analysis and discussions to set up a well-designed geodatabase along with the basic GIS functionalities that were needed. The first database structure was set up in 1990 and, after a huge effort of data digitization, the first operational system was achieved in 1996. Additional functionalities (Soutter and Mattei 2002) were developed in 2000-2002. In this development process, the focus was

\footnotetext{
${ }^{1}$ http://hydram.epfl.ch/gesreau
} 
mainly on quantitative water management issues, so that water quality was a bit left apart. From 2003 on, activities in the development of the water quality aspects started, with the first basis of a conceptual data model being established soon after (Gianella 2005) and then progressively refined.

Adapting this platform to the Romanian context goes along with an interest for the Swiss partners to possibly adapt the specific developments achieved in Romania, back in the initial framework in a so-called reverse adaptation process.

The structure of the partnership set up for the INWAQ (Development of an Integrated Water Quality Management System, with Application to the Ialomita River Basin) project thus associates a research institution and a public water authority, both in Switzerland (EPFL and SESA) and in Romania (Universitatea Tehnica de Constructii BucurestiUTCB - and Romania's National Water AdministrationANAR), with the ambition of achieving knowledge/technology transfers in both directions.

This paper briefly reviews the successive steps of the methodological process that has been applied in Romania and the results obtained. These results are then discussed, before a conclusion is drawn.

\section{Materials and methods}

Although the development of the operational GIS-based integrated management tool for the Romanian water administration is based on an already existing software platform, the same methodological approach as used previously in Switzerland was applied (Fig. 1, Schenk et al. 2007). The successive steps of this process are briefly outlined here:

- Stakeholder analysis The scope of this first and very important step is to identify the stakeholders involved in water management at the global (river basin and country wide) and local levels. This is a necessary step if one wishes to involve the broad spectrum of sometimes conflicting concerns about water management and a prerequisite for the assessment of needs. During software development, more than half the errors occurring are requirement errors (specifications don't match actual requirements, see for example Moody 2005).

- Assessment of needs This second step should as much as possible include all identified stakeholders. The assessment is targeted onto the various stakeholders needs, in terms of data and functionalities, according to their assignments. It includes the definition of the objectives pursued and the methods used, the list of available data and lacking data that would be needed to improve the fulfillment of the assignments, data acquisition priorities, and a list of needed and/or expected functionalities.

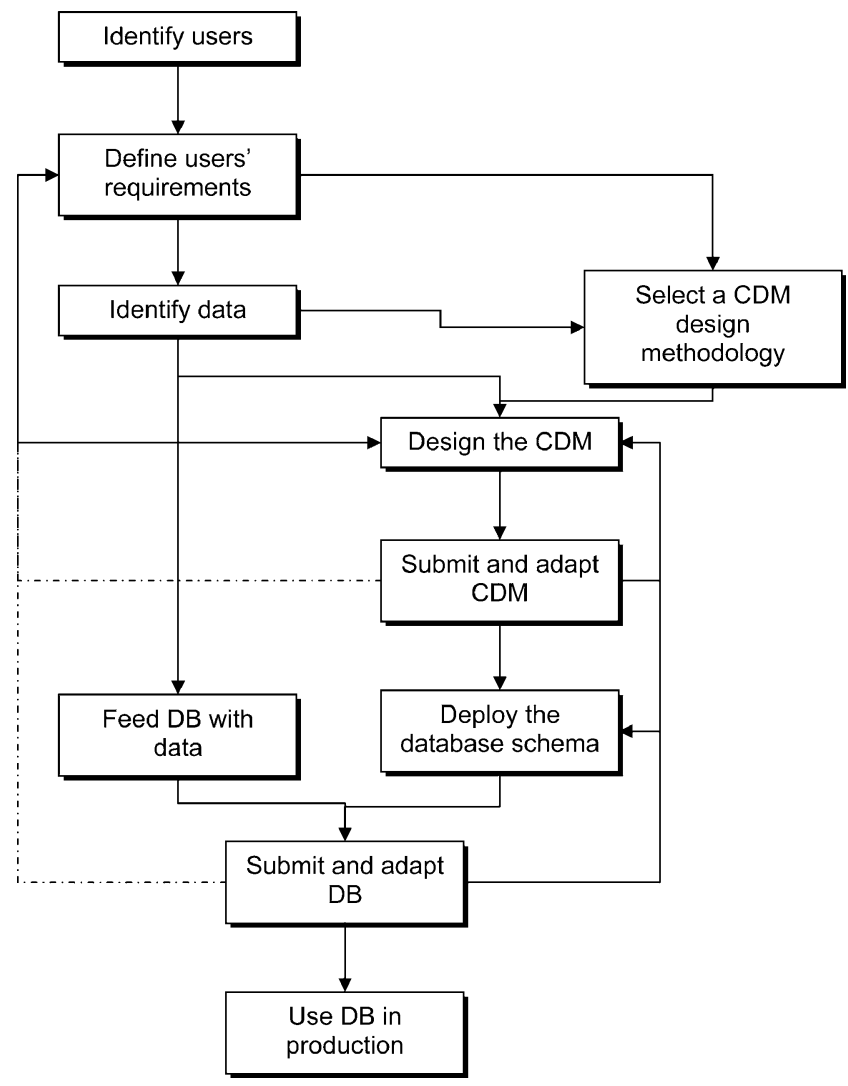

Fig. 1 Database development steps

- Conceptual data model The assessment of needs provides the necessary basis to the setup of a conceptual data model (a systemic vision of the various objects to be included in the data base, along with their attributes and their inter-relations) along with a descriptive list of the functionalities to be developed.

- Physical database and data acquisition The conceptual data model can be engineered into a physical database (a set of interlinked data tables in a database management software). These tables then need to be filled with data, acquired by the various usual means.

- Development of specific GIS functionalities Depending on the used GIS software, a large part of the needed functionalities will be present as part of the set of fundamental spatial analysis tools included in the software (visualization, edition, spatial selection, network functions, etc.). The various, more domainspecific functionalities identified during the assessment of the needs stage, then needs to be developed and included in the selected GIS platform.

This setup process is facilitated by the fact that a preexisting system can be used as a source of inspiration. It is further influenced by the overall context of water management in Romania, namely aspects such as the administrative layout 
or the EU water framework directive that sets the general duties of the public bodies in charge of water quality management. The current situation of water management in Romania, as well as the specific assignments of the water administration, has a strong impact on the needs and priorities.

\section{Results}

The results obtained from this action-research project consist of a set of tangible elements, among which (1) a conceptual data model adapted to the Romanian specificities regarding water resources management (needs, data availability, etc.), (2) a related spatial, relational database (objects and attributes in tables, links, etc.) that can be used to store the data collected, among others, by the water administration, and later on exploited with geographical information systems, (3) a toolbar (in the ESRI environment) offering the requested data processing and visualizing functionalities. Lessons learned from this whole process can be considered as additional, although less tangible, results and will be discussed later on.

\subsection{Stakeholder analysis and assessment of needs}

Public participation in implementing the Water Framework Directive is achieved in Romania by the setup of River Basin Committees. The members of these committees include (1) representatives of the central water and environment authorities, (2) a representative of the central health authority, (3) the mayors of three municipalities within the river basin, of which at least one mayor of a city, (4) a representative of NGO's having their headquarters in the river basin, (5) a prefect, from the river basin, as a representative from the central public administration, (6) the county council president of one of the river basin's counties, (7) three representatives of water users from within the river basin, (8) two representatives of the national water administration, and (9) a representative of the national authority for consumers protection.

Relevant stakeholders involved in water quality issues at the river basin scale include two groups: the first includes the authorities involved in the Water Framework Directive and other EU Directives implementation (Ministry of Environment and Water Management, National Administration of Water 'Apele Romane' and its branches: 11 Water Directorates and 41 Water Management Systems). The second group is composed of administrative bodies (prefectures, public health directorates, national, regional, and county environmental protection agencies, agricultural directorates, national and local consumer protection offices, etc.), other local authorities (mayoralties, county councils, etc.), water users (industry, agriculture, water service companies, power plants, etc.), universities, research units, mass media, and non-governmental organizations.

Assessing the needs of those two groups of stakeholders was done in three steps (Drobot et al. 2007): (1) inventory of their assignments or missions, (2) inventory of available and lacking data, and (3) inventory of requested functionalities. The first category of stakeholders, which includes the National Administration 'Apele Romane' with its branches, needs raw data to characterize the river basins. The main concerns are the evaluation of pressures and impacts on water bodies, in order to assess the fulfilment of the environmental objectives set by the Water Framework Directive. Another central issue is the need for data to assess the sustainability of water management, namely on the basis of an economic analysis of water resources allocation. The second group of stakeholder is mainly concerned by the various stages of the elaboration of the river basin management plans and the transposition of the European legislation to Romania; accessing to general information on environmental protection and human health, cost recovery of water-related infrastructures, and flood protection.

In the Ialomita river basin case, a fairly large amount of data on the water system is available, both regarding quantity and quality (surface water, groundwater, wastewater, waterrelated infrastructures, etc). Lacking data are mainly related to the biological status of water bodies (hardly monitored) and to their ecotoxicological status. In almost every domain, gaps in the spatial coverage of water-related data are reported. A catalogue of expected functionalities was established. They include simple basic functionalities, normally included in most current GIS software, such as viewing spatial objects and their attributes, or operating spatial and attributive requests and selections. The more specialized functionalities that were requested by the stakeholders in the Ialomita River basin were mostly linked to data management and treatment, and to water quality analysis and mapping. This reflects the absence of a computerized data management system, which is a prerequisite for other more elaborated GIS-linked applications, such as the coupling with simulation models (for example, nonpoint pollution models) that can be used to derive indicators that might be relevant in a decision-making process.

\subsection{Conceptual data model and setup of the database} for the Ialomita river basin

The conceptual data model was derived from the model used in the Swiss water resource management GIS Gesreau, with an adaptation to the Romanian context, special attention being paid to the Water Framework Directive and to other pre-existing databases in Romania (namely, the Cadaster database that inventories the waterrelated infrastructures). The complexity of such a data model is often difficult to conceive, if one is not really 
involved in understanding it, and almost worthless to try to present it in graphical form (Sugumaran and Storey 2002, 2006). Table 1 describes the nine modules that this CDM is made of.

Although quite abstract, the data model was discussed with and validated by the stakeholders. The model was then turned into a physical database (ESRI products), which could be progressively fed by a quite large set of existing data. Adding data to the geodatabase was actually far from a straightforward task since quite a lot of pre-processing was required (among others, to identify and document the meaning of the various attributes in existing data layers). As illustrated by Fig. 2, a quite consistent set of data could be set together on the Ialomita River basin.

\subsection{Specific tools - the GESRO toolbar}

The development of specific tools to address the needs revealed by the stakeholder analysis and the needs assessment formed the major part of this project. These tools are mainly meant to help address the central issue of the evaluation of the ecological status of rivers and other water bodies, keeping in mind that this is a very important and strongly binding aspect of the Water Framework Directive implementation (achieving good status by 2015).

The addressed domains and related indicators include (1) chemical indicators, (2) biological indicators, (3) dangerous substances, (4) drinking water, (5) fish population, and (6) vulnerability to nitrates. Thus, the set of developed tools, called GESRO, proposes an automatic way of determining the rivers' quality on the basis of measurements. The entire methodology is generally compliant with the EU Water Framework Directive, and specifically with the operational rules currently enforced within the Romanian National Water Administration. The GESRO application is written in Visual Basic on the ArcGIS platform. It can be seen as an extension of the standard ArcMap functionalities. GESRO is a user-friendly application which can be easily accessed by water specialists, even if they are not familiar with the ArcGIS environment.

The set of tools in the GESRO toolbar include (Fig. 3):

1. a selection tool to choose the indicator to work on

2. a data importation tool, to add data from external Excel files (tables or specific records)

3. a user-friendly data edition tool, to directly input new measurements. The data editor offers different specific layouts adapted to the type of indicators one is working with (see examples in Fig. 4)

4. a calculation tool. Calculation primarily concerns the aggregation of measured values (time averages, medians, etc.) and the determination of derived indicators (such as the saprobic index, for example), the classification of the river reach according to the various indicators and the calculation of the final overall quality class for mapping purposes

5. a tool to help identify potential pollution sources for contaminated river reaches. For a set of poor quality river reaches, this functionality basically performs an automatic upstream search to select potential pollution sources

6. a reporting tool that summarizes available data on a river reach and formats this information in a convenient

Table 1 Modules of the conceptual data model

\begin{tabular}{|c|c|c|}
\hline No.crt. & Module & Description \\
\hline 1 & River network & $\begin{array}{l}\text { Describes the geometric elements of the river network such as rivers, water bodies, } \\
\text { lakes }\end{array}$ \\
\hline 2 & River network characteristics & $\begin{array}{l}\text { Completes the river network module with point and linear events which occur on } \\
\text { rivers, quality segments, profiles, monitoring sections, processed data }\end{array}$ \\
\hline 3 & River basin & $\begin{array}{l}\text { Describes the basin geometry, the division in sub-basins, as well as its parameters } \\
\text { (slope, land use, soil, rainfall run-off coefficient, modeled discharges). The flood } \\
\text { problems are also treated in this module }\end{array}$ \\
\hline 4 & Aquifers & $\begin{array}{l}\text { This module refers to groundwaters. Groundwater bodies, wells (of the national } \\
\text { hydrogeological network or of other owners), geological, hydrogeological, } \\
\text { hydrochemical parameters are also included }\end{array}$ \\
\hline 5 & Indicators & $\begin{array}{l}\text { This module contains all physical, chemical, biological, biochemical indicators: } \\
\text { measured values, limits, monitoring programs }\end{array}$ \\
\hline 6 & Point pollution & Treats the accidental and systematic pollution problems \\
\hline 7 & $\begin{array}{l}\text { Hydraulic works of the generalized } \\
\text { river network }\end{array}$ & $\begin{array}{l}\text { Describes all types of hydraulic works located on the river (spatial positioning) } \\
\text { or near the river (dynamic segmentation) }\end{array}$ \\
\hline 8 & Settlements & $\begin{array}{l}\text { This module presents all villages, municipalities, towns from Ialomita river basin } \\
\text { which can be responsible for pollution or vulnerable against pollution and floods }\end{array}$ \\
\hline 9 & Documents & $\begin{array}{l}\text { This module puts together all necessary documents (normatives, mathematical } \\
\text { models, laws, scientific documents, multimedia documents) }\end{array}$ \\
\hline
\end{tabular}




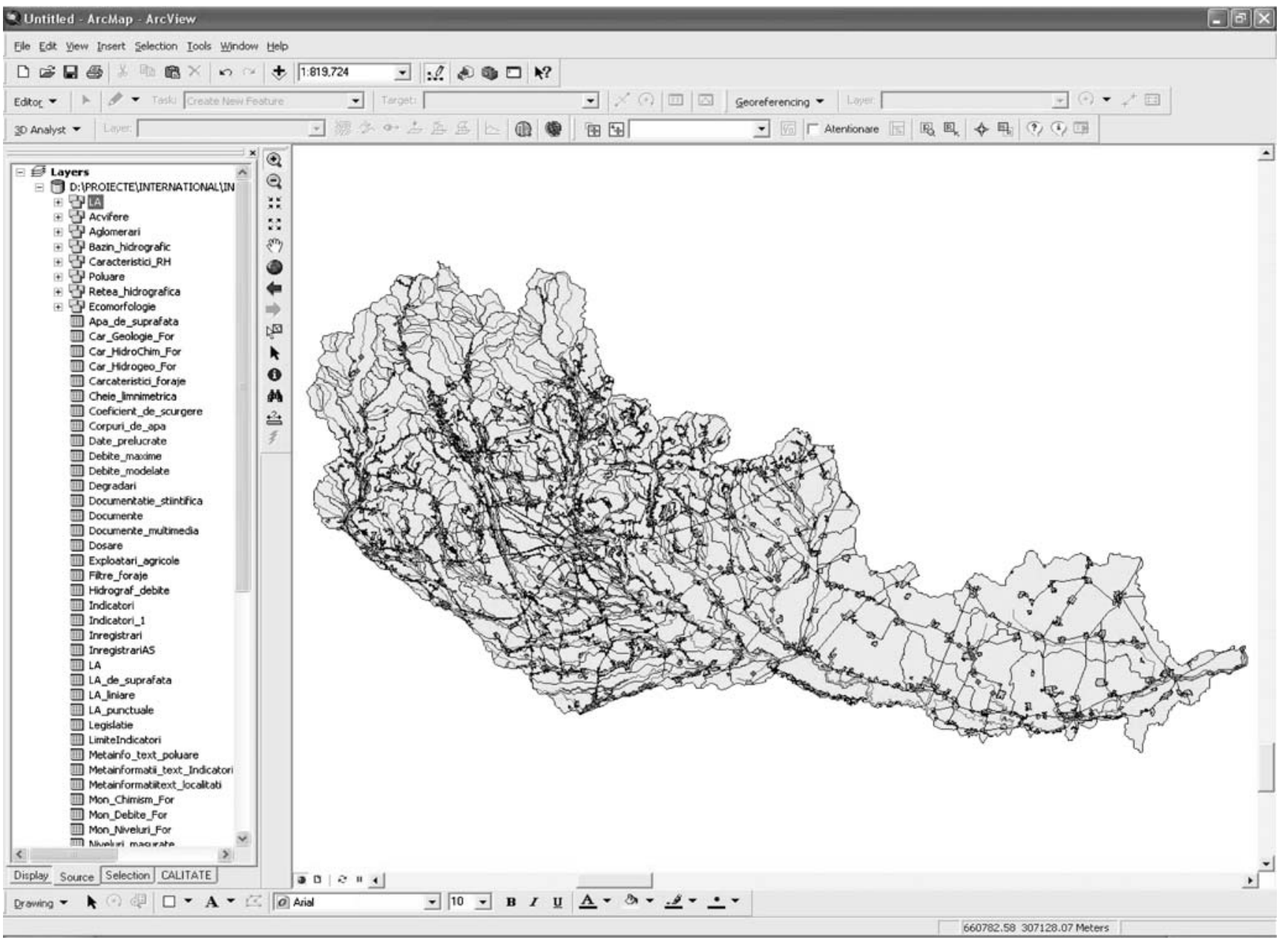

Fig. 2 Screenshot of the GIS platform

layout. A predefined reporting layout has been prepared for the six types of indicators listed above

7. a layout generator, to automatically create welldesigned maps, among others of the river quality status

8. a map export tool, to export these maps to image files

9. an online help, providing all necessary directions for an appropriate use of the toolbar

With this set of tools, the Romanian water authorities get an easy access to the whole chain of treatments that leads

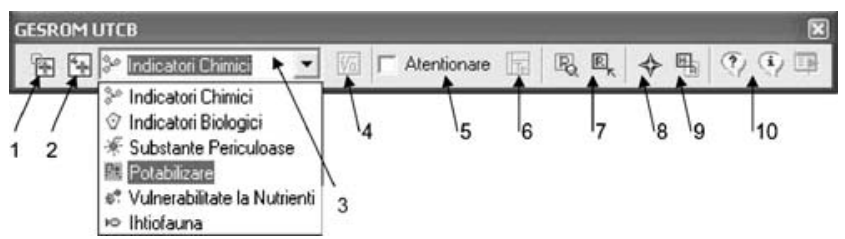

Fig. 3 The GESRO toolbar functional buttons (1-import data, 2add data, 3-tasks, 4-calculations, 5-list potential pollution sources, 6-tables, 7-reports, 8-generate layouts, 9-export the view to an image file, 10 - help and information) from data acquisition to environmental status assessment, with the necessary data processing, analysis, mapping and reporting stages (Alexandrescu et al. 2007).

\section{Discussion}

As a consequence of this action-research, demand-driven project, a strong emphasis was given to meeting the stakeholders' needs and much attention paid to dissemination: the developed tools were thus distributed among the eleven decentralized ANAR branch offices and at the central administration, along with a hands-on training session. The commitment of ANAR in the whole process and its willingness to go for further complementary developments beyond the end of the ESTROM program is a very positive indicator showing that the project was actually well appreciated. Another rather unexpected consequence of trying to adjust to the local actual needs is the fact that the whole process shifted slightly away from what was originally foreseen: due to the absence of a 


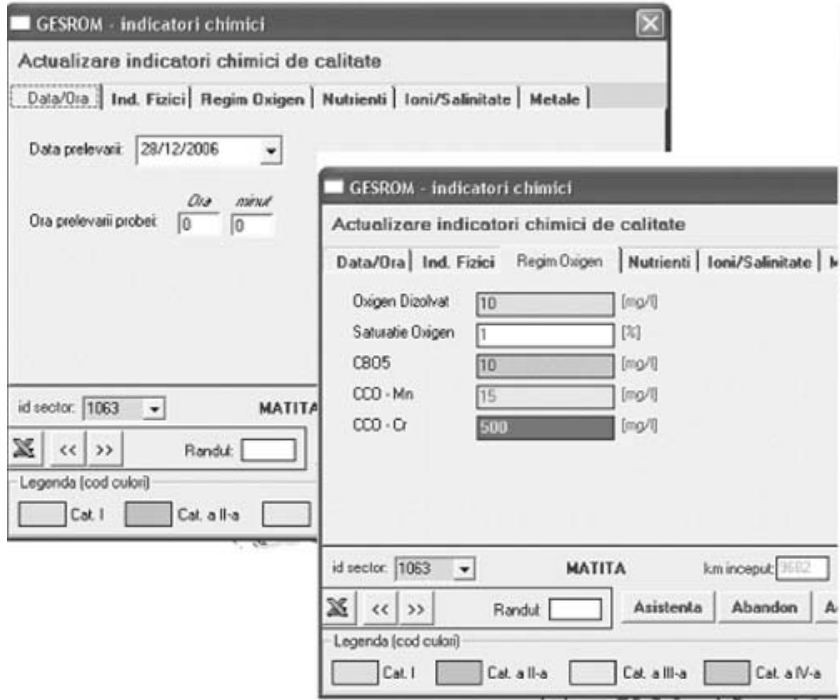

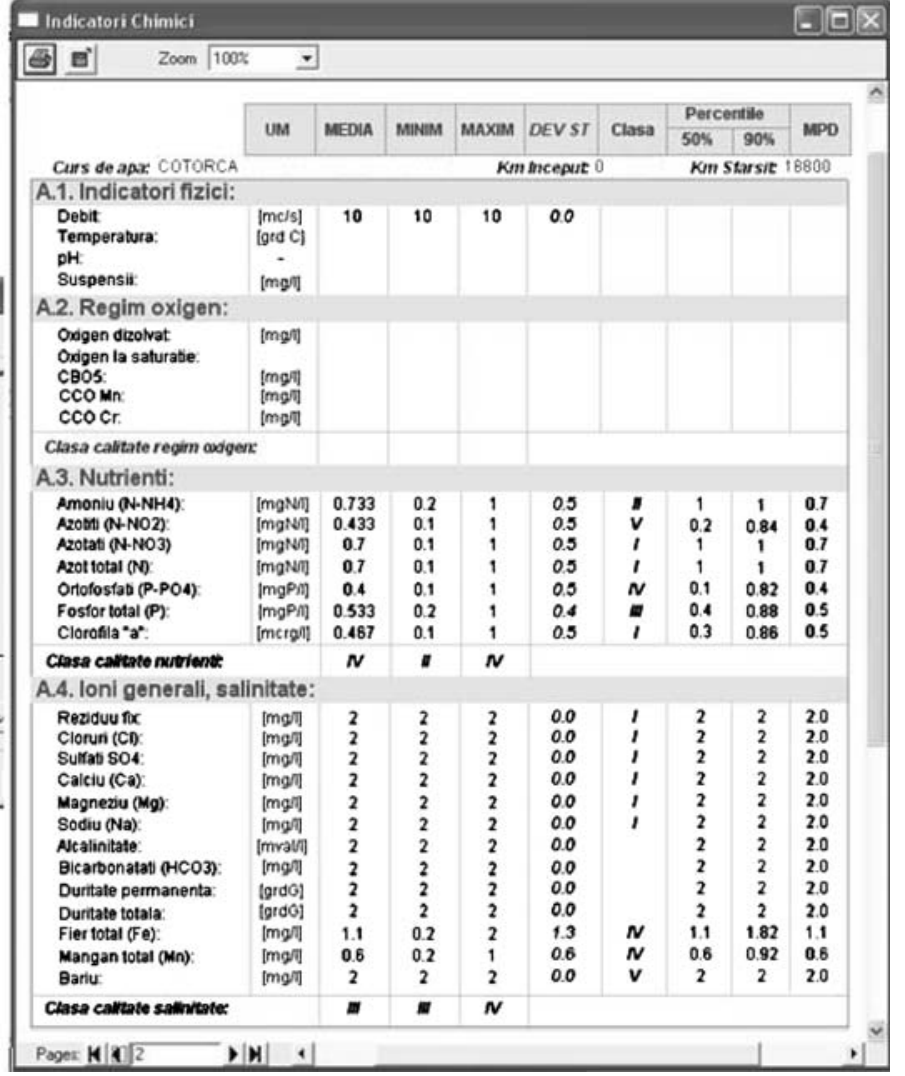

Fig. 4 Examples of data edition and reporting

general basic data management tool and since such a tool is a necessary prerequisite to setup a GIS system, much of the effort focused on developing adapted tools to process the water quality observations. As a consequence, the time/ energy available to develop water management specific tools, such as the coupling with simulation models or similar kind of functionalities, was reduced with respect to the initial expectation. This shift, however, is also to be considered as positive insofar it shows that we succeeded in meeting the real day-to-day working needs of the involved stakeholders.

Less positive is the adverse effect of this shift on the reverse adaptation of the Romanian developments to the Swiss context. This important win-win aspect of the project appears to be much less straightforward than expected, since most cantons in Switzerland (and this is the case in canton de Vaud) make use of specific, independent, usually non-spatial, database systems to handle their data (chemical or biological monitoring, for instance). In that case, the GIS layer comes on top of such domain-specific databases to which it is more or less tightly coupled. The fact is that the data handling processes are not really interesting for the Swiss administrative partner, but the spatial components are. The feasibility of separating both aspects reasonably easily is currently still under evaluation.
Another interesting aspect of the technology transfer dimension of the INWAQ project relates to the methodological approach and, more specifically, the development of an adapted specific conceptual data model: this approach and the related concepts were not familiar at all to our Romanian partners. It was perceived as a rather complicated way to address not so complex issues. To this respect, the time period available to set up such an approach is probably very critical: we tried to replicate, within a few months, a process that extended originally over a much longer time period (several years actually). Explanations and progressive understanding are part of a long-lasting maturation process that cannot be achieved in a few short steps. Efficient communication needs time (see also Moody 2004). Anyway, this lack of time to 'digest' the concepts which resulted in a simplification of the data model into something may be more intuitive and easier to understand. Dynamic segmentation (the ability to represent any attribute on a river on the basis of a single polyline object and an indirect table giving the attribute's value according to the distance along this line), in particular, was left apart, to work with a 'crisp', cut-down of rivers into segments. This fundamental difference in handling the river network's geometry is an additional difficulty to the reverse adaptation process. 
Apart from the process of applying this methodology in a quite different context with a quite different background, it is only possible to provide an integrated view on water quantity and quality, within a GIS frame, to end-users, thus allowing them to have an easier access to global displays and analyses. With such global perceptions, they will achieve a better understanding of the overall situation regarding different pollutants, especially with respect to their chronological (trends) and spatial evolutions, but also in view of inter-comparisons and possible interdependencies. The spatial representation also provides a better understanding of the relations between the pollutants and their environment (potential anthropogenic and natural sources, punctual and diffuse pollution, effect of infrastructure and of non-structural measures, interactions/impacts on aquatic systems and animals, etc.). In a more practical way, a water resource management GIS provides tools that can be used to analyse the spatial relations between pollution sources, the state of pollutants in the waters and important fragile water-related areas (wetlands, alluvial areas, protection areas for drink water supply, etc.). Integration helps to better understand and evaluate effective impacts of water pollution on ecosystems and human health. As a consequence, these tools also provide a useful basis to identify adequate strategies, at the river basin scale, to define water quality management strategies that include a coherent set of mitigation and/or remediation measures (Geertman and Stillwell 2003).

Considering the overall general ESTROM objective of improving water quality in Romania, it is believed that setting up a framework to better manage and interlink water related information is a major step towards making better decisions in the field of water management. The INWAQ project is thus an important contribution in achieving the goals of the ESTROM program. Finally, GIS environments show the advantage of being a neutral communication platform, offering thus a good support to decision making. The ability to spatially display problems, concerns and possible solutions, is very attractive to decision makers, which definitely requires communication facilities. The whole chain going from problem assessments and analyses, identification and localization of mitigation measures, evaluation of potential future impacts and a follow-up of interventions, can be organized within such monitoring tools.

\section{Conclusions}

This research showed that a GIS-based water management system needs to be backed by some basic data management tools that form the necessary support upon which a GIS can be deployed. The main lesson gained is that technology transfer in general has to pay much attention to the differences in existing situations and backgrounds, and therefore be able to show much flexibility. The fact that the original objectives could be adapted to meet the real needs of the local end-users is considered as a major aspect in achieving a successful adaptation and development of water resources management tools. Time needed to set up things in real life was probably the most underestimated aspect in this technology transfer process.

\section{Recommendations and perspectives}

The whole material produced (conceptual data model, database and GIS tools) was disseminated among all river basin authorities in Romania on the behalf of the national water administration (ANAR). The fact that further developments, to address for example more precisely water quantity issues, are envisaged by ANAR can be seen as an indication that this project succeeded in providing an appropriate input to improve water quality in Romania on the long term.

Acknowledgement This work was financed by the Swiss National Science Foundation, the Swiss Agency for Development and Cooperation and the Romanian Ministry for Education and Research within the framework of the Swiss-Romanian cooperation program on 'Environmental Science and Technology in Romania-ESTROM'. The reported study was performed in the project INWAQ focusing on the setup of a GIS-based water quality management system, adapted to the Romanian context on the basis of the Ialomita experimental river basin.

\section{References}

Abbot J, Chambers R, Dunn C, Harris T, de Merode E, Poter G (1998) Participatory GIS: opportunity or oxymoron? IIED PLA Notes 33:27-33

Alexandrescu M, Marinescu M, Tuchiu E, Gheorghe V, Teodor D, Cheveresan B, Ichim L, Schenk C, Soutter M, Vasiu A, Drobot R (2007) The management of the quality water resources in Ialomita River Basin. Institutul National de Hidrologie si Gospodarire a Apelor, Conferinta stiintifica anuala, Bucarest

Borja J, Castells M (1997) Local and global management of cities in the information age. Earthscan, London

Drobot R, Alexandrescu M, Laurentiu I, Cheveresan B, Marinescu M, Vasiu A, Tuchiu E, Schenk C, Soutter M (2007) Integrated water quality management system INWAQ (Ialomita river basin Romania). IUGG 2007 conference, Perugia

EU (2003) Implementing the geographical information system elements (GIS) of the water framework directive. Office for official publications of the European communities. Luxembourg. ISBN 92-894-5129-7

Geertman S, Stillwell J (2003) Planning support systems: an introduction. In: Geertman S, Stillwell J (eds) Planning support systems in practice. Springer, New York, pp 3-22

Gianella S (2005) Strategisches Informationsmanagement für die Abwasserentsorgung. Diss. ETH Nr. 16045, Zurich 
Lyon JG (2002) GIS for water resources and watershed management. Lyon JG (ed) Taylor \& Francis, London

Mattei A, Soutter M (2008) GESREAU: Entwicklung von Tools für die Bewirtschaftung der Wasserressourcen. Proceedings GIS/ SIT2008, Basel

MDDEP (2002) L'eau. La vie. L'avenir. Politique nationale de l'eau. Ministère du développement durable, de l'environnement et des parcs du Québec. ISBN 2-550-40074-7, http://www.mddep. gouv.qc.ca/eau/politique/politique-integral.pdf

Moody DL (2004) Cognitive load effects on end user understanding of conceptual models: an experimental analysis. Advances in Databases and Information Systems, Proceedings 3255:129143
Moody DL (2005) Theoretical and practical issues in evaluating the quality of conceptual models: current state and future directions. Data Knowl Eng 55:243-276

Schenk C, Soutter M, Roquier B, Mermoud A (2007) A system model for water management. Environ Manage

Soutter M, Mattei A (2002) GESREAU: développement d'outils d'exploitation d'une base de données relative à la gestion des ressources en eau. Proceedings GIS/SIT2002, Zurich

Sugumaran V, Storey VC (2002) Ontologies for conceptual modeling: their creation, use, and management. Data Knowl Eng 42:251-271

Sugumaran V, Storey VC (2006) The role of domain ontologies in database design: An ontology management and conceptual modeling environment. Acm T Database Syst 31:1064-1094 